\title{
Medical Costs by Disease Stage in Medicare Patients with Metastatic Melanoma
}

\author{
Amanda M. Farr ${ }^{1}$, Zhongyun Zhao ${ }^{2}$, Xue Song1 ${ }^{*}$, Beth Barber ${ }^{2}$, Boris Ivanov ${ }^{1}$, Marilyn Novich1 \\ ${ }^{1}$ Life Sciences, Truven Health Analytics, IBM Company, Cambridge, MA, USA \\ ${ }^{2}$ Global Health Economics, Amgen Inc., Thousand Oaks, CA, USA \\ Email: ^songx@us.ibm.com
}

How to cite this paper: Farr, A.M., Zhao, Z.Y., Song, X., Barber, B., Ivanov, B. and Novich, M. (2017) Medical Costs by Disease Stage in Medicare Patients with Metastatic Melanoma. Journal of Cancer Therapy, 8, 913-923.

https://doi.org/10.4236/jct.2017.811080

Received: May 5, 2017

Accepted: November 5, 2017

Published: November 8, 2017

Copyright (c) 2017 by authors and Scientific Research Publishing Inc. This work is licensed under the Creative Commons Attribution International License (CC BY 4.0).

http://creativecommons.org/licenses/by/4.0/

\begin{abstract}
Background: Melanoma is a rare but serious skin cancer that is responsible for $>90 \%$ of skin cancer-related deaths. This retrospective data analysis quantifies the direct cost of medical care by disease stage at diagnosis for patients with metastatic melanoma. Methods: The Surveillance, Epidemiology, and End Results (SEER)-Medicare database was queried for patients diagnosed between 2004-2009 with stage IIIB/C and stage IV (M1a, M1b, M1c) melanoma. The primary outcome was overall medical utilization and associated costs from diagnosis to death, the end of Medicare enrolment, or 12/31/2010. Results are stratified by disease stage at diagnosis and presented as per-patient per-month (PPPM) costs. Results: Of the 1263 patients meeting the study criteria (mean age: 75 years; $64 \%$ male, $92 \%$ white, mean duration of follow up: 37.5 months), $66.6 \%$ were diagnosed at stage IIIB/C and $33.4 \%$ at stage IV. Cost of care increased with disease stage. Total PPPM costs ranged from $\$ 1966$ for patients diagnosed with stage IIIB to $\$ 4585$ among patients diagnosed with stage M1c. Outpatient costs accounted $48.9 \%$ of total medical costs among stage IIIB patients, and $38.7 \%$ of total medical costs for stage M1c patients. Inpatient costs accounted for $37.1 \%$ (stage M1b) - 40.9\% (stage M1c) of total medical costs. Conclusions: Healthcare costs for treating patients with metastatic melanoma increase by disease stage. The cost of care was more than double among patients with late stage compared to those with early stage. Treatments demonstrating ability to prevent disease progression from early stage to late stage may confer an economic benefit among other clinical advantages.
\end{abstract}

\section{Keywords}

Melanoma, Healthcare Costs, Disease Stage, Medicare 


\section{Introduction}

Melanoma is a rare but serious skin cancer that can rapidly infiltrate deep, vascular skin layers, and it commonly metastasizes very early [1] [2]. Although melanoma affects people of all ages, $34 \%$ of patients are younger than 55 years at diagnosis [3]. Among people with metastatic melanoma, survival data from real-world clinical practice consistently show that survival differs greatly by stage of disease [4] [5]. In a study of patients with metastatic melanoma from the Surveillance, Epidemiology, and End Results (SEER) database, patients with unresectable (no curative resection was performed) non visceral disease (stages IIIB or IIIC or M1a) had a median overall survival (OS) of 22 to 24 months [5]. Those with distant metastasis to the lung (stage M1b) - with or without skin or subcutaneous metastases-had a median OS of 11 months [5]. The poorest survival duration was observed in patients with metastases to other visceral sites (stage M1c), who had a median OS of 5 months [5].

Melanoma is a devastating disease with economic implications for individuals, their families, and society. A systematic review by Guy and colleagues found that medical costs were higher among patients diagnosed with late-stage melanoma compared to those diagnosed at early-stage disease [6]. However, these studies either used very old data (e.g., SEER-Medicare 1991-1996 and 1999-2003), were based on very small sample sizes, or conducted outside the US. Few recent studies have quantified the direct healthcare costs by disease stage accrued by patients diagnosed with metastatic melanoma. One of the reasons for lack of studies on costs by disease stage in metastatic melanoma is that insurance medical claims databases usually do not have accurate disease stage information while melanoma registry databases do contain stage information but often do not have healthcare resource use and cost information.

This study describes the medical utilization and costs of patients with metastatic melanoma by stage of disease from the payer's perspective, using more recent SEER-Medicare data that had information on both cost and disease stage in the US. Stage of disease was based on the American Joint Committee on Cancer (AJCC) $6^{\text {th }}$ edition staging system [7].

\section{Methods}

\subsection{Data Sources}

This analysis utilized two linked data sources: the SEER cancer registry and Medicare claims. The SEER database is a unique population-based cancer registry containing cancer staging at the time of diagnosis and survival time for residents in 18 geographic areas in the US, representing $26 \%$ of the nation's population [8]. Hospitals, laboratories and physician offices populate the SEER database by sending information on incident cancer cases, including clinical and patient information, such as staging and planned course of treatment. The SEER database is routinely updated with vital status information collected through active follow-up with clinical sources as well as annual passive data transfer with 
other organizations, including state vital records departments and the Social Security Administration [9] [10].

The SEER registry was first linked to Medicare claims data in 1991, allowing researchers to conduct additional clinical and economic analyses [11]. More than $90 \%$ of the SEER melanoma cases among patients aged 65 years or older are linked to Medicare claims data [10]. The Medicare claims data include inpatient hospitalizations (Medicare Part A) and outpatient medical services (Medicare Part B), including diagnoses, procedures, and payments for patients enrolled in Medicare. The most recent SEER data available at the start of this analysis were from the November 2011 submission and included cancer diagnoses from 1973 through 2009 with a follow-up cut-off date of December 31, 2009. The cut-off date for Medicare claims was December 31, 2010.

The New England Institutional Review Board (NEIRB) reviewed the study design and the proposed data sources for this study, and because the study used only de-identified patient records and did not involve the collection, use, or transmittal of individually identifiable data, the study was deemed exempted from the NEIRB review.

\subsection{Study Population}

The study population comprised patients diagnosed with stage IIIB, IIIC, or IV (M1a-c) melanoma (based on the AJCC $6^{\text {th }}$ edition staging system) between January 2004 and December 2009, and whose data were successfully extracted from the SEER database and linked to the Medicare claims data. Melanoma cases were identified using the SEER site recode value "25010" which is equivalent to International Classification of Diseases for Oncology, Second Edition (ICD-O-2) topography codes C44.x and International Classification of Diseases for Oncology, Third Edition (ICD-O-3) morphology codes 8720 - 8790. As the SEER data only contains month and year of diagnosis, the index date of melanoma diagnosis was assumed to be the first day of the month. Patients were excluded from the study if their melanoma was identified at autopsy or on a death certificate, or if they were not enrolled in Medicare for the month during which they were diagnosed.

Patients were followed from the index date to the earliest of the following events: death, end of enrolment in Medicare, or the end of the Medicare claims follow-up period (December 31, 2010). Demographic and clinical characteristics were determined based on SEER information at the index date and included age, gender, race, evidence of prior cancer diagnosis, year of melanoma diagnosis, and stage. Medicare enrolment files were examined up to 6 months prior to the index date through the end of follow-up period to flag patients who were enrolled in a health maintenance organization (HMO) plan, as these patients may not have complete Medicare claims. For patients in HMO plans, their observed healthcare utilization and costs were used in the analyses and the percentage of patients with HMO was reported. Sensitivity analysis was also conducted in the 
subset of patients with no HMO.

\subsection{Outcomes}

All-cause medical utilization and direct costs were captured during the follow-up period. Utilization was measured as the presence of at least one claim for the following service types: inpatient admissions, skilled nursing facilities (SNFs), emergency department (ED) visits, outpatient office visits, home healthcare (HHC), hospice, and other outpatient services. Costs were the amount reimbursed by Medicare to providers, not including the amount paid by the primary payer other than Medicare or patient out-of-pocket costs. Costs were adjusted to 2015 US dollars using the medical component of the Consumer Price Index. Total costs as well as costs for the service types detailed above were examined. To account for the variable length of follow up, total costs and cost components are reported per-patient-per-month (PPPM) and stratified by stage at diagnosis.

\subsection{Statistical Analyses}

Descriptive analyses were conducted to examine patient characteristics and mean direct medical costs. Total costs and costs by place of service are reported for each stage at diagnosis. Means and standard deviations were computed for continuous variables while proportions were computed for categorical variables. Statistical significance testing was conducted among disease stages, with ANOVA tests on continuous variables and Chi-squared tests on proportions.

\section{Results}

From 2004 to 2009, 87,183 melanoma cases were identified in SEER and linked to Medicare claims. Of these, 4076 were diagnosed at stage III or stage IV disease. The final sample included 1263 patients who had at least one month of enrolment in Medicare following their index date. Nearly two-thirds of the sample was diagnosed at stage IIIB or stage IIIC. (Table 1) The mean (standard deviation (SD)) age was 75 (9.3) years. Over $60 \%$ of patients were between 65 and 85 and just over $20 \%$ were between 50 and 64 . The majority of patients were male and white. The proportion of patients who had at least one prior cancer diagnosis according to SEER data ranged from $31.3 \%$ to $50.9 \%$ and was higher among stage IV patients. Additionally, approximately one-third (26.5\% - 36.7\%) of patients were enrolled in an HMO during the 6 months prior to the index date or during follow-up. The average duration of follow up was 37.5 months (median = 33 months). Those with stage IIIB melanoma had the longest duration of follow-up, while those diagnosed at a later stage (M1c) had the shortest.

A high proportion of patients received healthcare services in hospitals, SNF/HHC, and ER, regardless of their stage of melanoma at diagnosis. Across all stages at diagnosis, approximately $70 \%$ of patients had an inpatient admission, $20 \%$ had a SNF stay or HHC visit, and half were seen in the ER. The proportion 
Table 1. Characteristics of patients diagnosed with advanced melanoma and enrolled in Medicare, by stage of disease at diagnosis.

\begin{tabular}{|c|c|c|c|c|c|}
\hline & \multicolumn{5}{|c|}{ Stage of Melanoma at Diagnosis } \\
\hline & $\begin{array}{l}\text { Stage } \\
\text { IIIB }\end{array}$ & $\begin{array}{l}\text { Stage } \\
\text { IIIC }\end{array}$ & $\begin{array}{l}\text { Stage } \\
\text { M1a }\end{array}$ & $\begin{array}{l}\text { Stage } \\
\text { M1b }\end{array}$ & $\begin{array}{l}\text { Stage } \\
\text { M1c }\end{array}$ \\
\hline & $\mathrm{N}=550$ & $\mathrm{~N}=291$ & $N=147$ & $\mathrm{~N}=112$ & $\mathrm{~N}=163$ \\
\hline Age, mean (SD) & $75.6(9.3)$ & $73.6(10.6)$ & $75.9(8.9)$ & $75.9(7.5)$ & $74.3(7.4)$ \\
\hline Median & 76 & 75 & 76 & 76 & 74 \\
\hline Male & $64.5 \%$ & $63.2 \%$ & $63.9 \%$ & $67.9 \%$ & $64.5 \%$ \\
\hline White & $92.7 \%$ & $90.0 \%$ & $90.5 \%$ & $99.1 \%$ & $92.6 \%$ \\
\hline $\begin{array}{c}\text { Mean follow-up in } \\
\text { Medicare in months (SD) }\end{array}$ & $43.6(22.4)$ & $35.6(21.8)$ & $36.3(21.5)$ & $31.6(21.4)$ & $25.5(20.6)$ \\
\hline Median & 41.5 & 29 & 30 & 24.5 & 19 \\
\hline $\begin{array}{l}\text { Enrolled in a health } \\
\text { maintenance } \\
\text { organization (HMO) }\end{array}$ & $32.0 \%$ & $26.5 \%$ & $36.7 \%$ & $36.6 \%$ & $29.4 \%$ \\
\hline $\begin{array}{c}\text { Year of melanoma } \\
\text { diagnosis }\end{array}$ & & & & & \\
\hline 2004 & $17.1 \%$ & $16.2 \%$ & $13.6 \%$ & $11.6 \%$ & $20.9 \%$ \\
\hline 2005 & $18.4 \%$ & $19.9 \%$ & $22.4 \%$ & $19.6 \%$ & $14.1 \%$ \\
\hline 2006 & $20.7 \%$ & $18.2 \%$ & $15.6 \%$ & $13.4 \%$ & $18.4 \%$ \\
\hline 2007 & $19.1 \%$ & $17.2 \%$ & $17.7 \%$ & $24.1 \%$ & $19.6 \%$ \\
\hline 2008 & $21.3 \%$ & $23.4 \%$ & $23.1 \%$ & $20.5 \%$ & $20.9 \%$ \\
\hline 2009 & $3.5 \%$ & $5.2 \%$ & $7.5 \%$ & $10.7 \%$ & $6.1 \%$ \\
\hline $\begin{array}{l}\text { Evidence of prior } \\
\text { cancer in SEER data }\end{array}$ & $38.0 \%$ & $31.3 \%$ & $40.1 \%$ & $50.9 \%$ & $48.5 \%$ \\
\hline
\end{tabular}

HMO: health maintenance organization; SD: standard deviation; SEER: Surveillance, Epidemiology, and End Results.

with a hospice stay did appear to vary by stage at diagnosis, from $34.0 \%$ among those diagnosed at stage IIIB to $66.3 \%$ of those diagnosed at stage M1c ( $\mathrm{p}<$ 0.001). Cost of care increased more noticeably with stage of diagnosis. Total PPPM costs ranged from $\$ 1966$ among those with stage IIIB melanoma to $\$ 4585$ among those diagnosed at stage M1c $(\mathrm{p}<0.001)$ (Table 2). The primary cost driver was outpatient costs (ER, office visits plus other outpatient services), which was almost twice as much in stage M1c as those in stage IIIB (\$1774 vs. $\$ 962, \mathrm{p}<0.001)$ and accounted for nearly half $(48.9 \%)$ of total medical costs among stage IIIB patients, and over one-third of total medical costs (38.7\%) for stage M1c patients. Inpatient costs more than doubled from stage IIIB to M1c (\$729 - \$1874 PPPM, p < 0.001), accounting for 37.1\% for stage IIIB patients and $40.9 \%$ for stage M1c patients of total medical costs (Figure 1).

\section{Discussion}

This analysis of patients diagnosed with metastatic melanoma between 2004 and 
Table 2. Per-patient per-month (PPPM) all-cause direct medical utilization and costs for patients diagnosed with advanced melanoma, by stage of disease at diagnosis.

\begin{tabular}{|c|c|c|c|c|c|c|}
\hline & \multicolumn{5}{|c|}{ Stage of Melanoma at Diagnosis } & \multirow{3}{*}{$\mathrm{p}$ value } \\
\hline & \multirow{2}{*}{$\begin{array}{c}\text { Stage IIIB } \\
\mathrm{N}=550\end{array}$} & \multirow{2}{*}{$\begin{array}{l}\text { Stage IIIC } \\
\qquad \mathrm{N}=291\end{array}$} & \multirow{2}{*}{$\begin{array}{c}\text { Stage M1a } \\
\qquad \mathrm{N}=147\end{array}$} & \multirow{2}{*}{$\begin{array}{c}\text { Stage M1b } \\
\mathrm{N}=112\end{array}$} & \multirow{2}{*}{$\begin{array}{c}\text { Stage M1c } \\
\mathrm{N}=163\end{array}$} & \\
\hline & & & & & & \\
\hline $\begin{array}{c}\text { Total mean } \\
\text { PPPM costs }(\mathrm{SD})\end{array}$ & $\begin{array}{c}\$ 1966 \\
(\$ 2303)\end{array}$ & $\begin{array}{c}\$ 2716 \\
(\$ 2930)\end{array}$ & $\begin{array}{c}\$ 2419 \\
(\$ 2891)\end{array}$ & $\begin{array}{c}\$ 3402 \\
(\$ 3804)\end{array}$ & $\begin{array}{c}\$ 4585 \\
(\$ 4153)\end{array}$ & $<0.001$ \\
\hline \multicolumn{7}{|l|}{$\begin{array}{l}\text { Inpatient } \\
\text { admission }\end{array}$} \\
\hline $\begin{array}{l}\text { Patients with } \geq 1 \\
\text { admission }\end{array}$ & $69.1 \%$ & $80.4 \%$ & $70.1 \%$ & $76.8 \%$ & $75.5 \%$ & 0.006 \\
\hline $\begin{array}{l}\text { Mean PPPM } \\
\text { costs (SD) }\end{array}$ & $\begin{array}{c}\$ 729 \\
(\$ 1285)\end{array}$ & $\begin{array}{c}\$ 1104 \\
(\$ 1740)\end{array}$ & $\begin{array}{c}\$ 954 \\
(\$ 1932)\end{array}$ & $\begin{array}{c}\$ 1227 \\
(\$ 1967)\end{array}$ & $\begin{array}{c}\$ 1874 \\
(\$ 2668)\end{array}$ & $<0.001$ \\
\hline \multicolumn{7}{|l|}{$\begin{array}{l}\text { Skilled nursing } \\
\text { facility stay }\end{array}$} \\
\hline $\begin{array}{c}\text { Patients } \\
\text { with } \geq 1 \text { stay }\end{array}$ & $18.4 \%$ & $20.3 \%$ & $14.3 \%$ & $21.4 \%$ & $21.5 \%$ & 0.455 \\
\hline $\begin{array}{l}\text { Mean PPPM } \\
\text { costs (SD) }\end{array}$ & $\begin{array}{c}\$ 122 \\
(\$ 386)\end{array}$ & $\begin{array}{c}\$ 152 \\
(\$ 552)\end{array}$ & $\begin{array}{c}\$ 69 \\
(\$ 231)\end{array}$ & $\begin{array}{c}\$ 157 \\
(\$ 584)\end{array}$ & $\begin{array}{c}\$ 358 \\
(\$ 1416)\end{array}$ & 0.001 \\
\hline \multicolumn{7}{|l|}{$\begin{array}{l}\text { Emergency } \\
\text { room visit }\end{array}$} \\
\hline $\begin{array}{c}\text { Patients } \\
\text { with } \geq 1 \text { visit }\end{array}$ & $56.4 \%$ & $56.4 \%$ & $53.1 \%$ & $55.4 \%$ & $60.1 \%$ & 0.803 \\
\hline $\begin{array}{l}\text { Mean PPPM } \\
\text { costs (SD) }\end{array}$ & $\begin{array}{c}\$ 24 \\
(\$ 49)\end{array}$ & $\begin{array}{c}\$ 32 \\
(\$ 64)\end{array}$ & $\begin{array}{c}\$ 23 \\
(\$ 45)\end{array}$ & $\begin{array}{c}\$ 30 \\
(\$ 49)\end{array}$ & $\begin{array}{c}\$ 52 \\
(\$ 114)\end{array}$ & $<0.001$ \\
\hline \multicolumn{7}{|l|}{$\begin{array}{l}\text { Outpatient } \\
\text { office visit }\end{array}$} \\
\hline $\begin{array}{c}\text { Patients } \\
\text { with } \geq 1 \text { visit }\end{array}$ & $79.3 \%$ & $77.7 \%$ & $80.3 \%$ & $78.6 \%$ & $81.0 \%$ & 0.930 \\
\hline $\begin{array}{l}\text { Mean PPPM } \\
\text { costs (SD) }\end{array}$ & $\begin{array}{c}\$ 202 \\
(\$ 317)\end{array}$ & $\begin{array}{c}\$ 229 \\
(\$ 339)\end{array}$ & $\begin{array}{c}\$ 240 \\
(\$ 323)\end{array}$ & $\begin{array}{c}\$ 311 \\
(\$ 513)\end{array}$ & $\begin{array}{c}\$ 358 \\
(\$ 524)\end{array}$ & $<0.001$ \\
\hline \multicolumn{7}{|l|}{$\begin{array}{l}\text { Home health } \\
\text { care visit }\end{array}$} \\
\hline $\begin{array}{c}\text { Patients } \\
\text { with } \geq 1 \text { visit }\end{array}$ & $18.2 \%$ & $24.7 \%$ & $13.6 \%$ & $17.9 \%$ & $16.6 \%$ & 0.040 \\
\hline $\begin{array}{c}\text { Mean PPPM } \\
\text { costs (SD) }\end{array}$ & $\begin{array}{c}\$ 28 \\
(\$ 100)\end{array}$ & $\begin{array}{c}\$ 42 \\
(\$ 126)\end{array}$ & $\begin{array}{l}\$ 21 \\
(\$ 86)\end{array}$ & $\begin{array}{c}\$ 32 \\
(\$ 152)\end{array}$ & $\begin{array}{c}\$ 49 \\
(\$ 179)\end{array}$ & 0.165 \\
\hline \multicolumn{7}{|l|}{ Hospice stay } \\
\hline $\begin{array}{c}\text { Patients } \\
\text { with } \geq 1 \text { stay }\end{array}$ & $34.0 \%$ & $45.7 \%$ & $42.9 \%$ & $54.5 \%$ & $66.3 \%$ & $<0.001$ \\
\hline $\begin{array}{c}\text { Mean PPPM } \\
\text { costs (SD) }\end{array}$ & $\begin{array}{c}\$ 124 \\
(\$ 344)\end{array}$ & $\begin{array}{c}\$ 202 \\
(\$ 500)\end{array}$ & $\begin{array}{c}\$ 281 \\
(\$ 830)\end{array}$ & $\begin{array}{c}\$ 560 \\
(\$ 1872)\end{array}$ & $\begin{array}{c}\$ 531 \\
(\$ 1003)\end{array}$ & $<0.001$ \\
\hline \multicolumn{7}{|l|}{$\begin{array}{l}\text { Other outpatient } \\
\text { services }\end{array}$} \\
\hline $\begin{array}{l}\text { Patients with } \geq 1 \\
\text { service }\end{array}$ & $82.9 \%$ & $84.2 \%$ & $83.7 \%$ & $82.1 \%$ & $85.9 \%$ & 0.900 \\
\hline $\begin{array}{c}\text { Mean PPPM } \\
\text { costs (SD) }\end{array}$ & $\begin{array}{c}\$ 736 \\
(\$ 1006)\end{array}$ & $\begin{array}{c}\$ 955 \\
(\$ 1142)\end{array}$ & $\begin{array}{c}\$ 832 \\
(\$ 1005)\end{array}$ & $\begin{array}{c}\$ 1084 \\
(\$ 1216)\end{array}$ & $\begin{array}{c}\$ 1364 \\
(\$ 1573)\end{array}$ & $<0.001$ \\
\hline
\end{tabular}

PPPM: per-patient per-month; SD: standard deviation. 


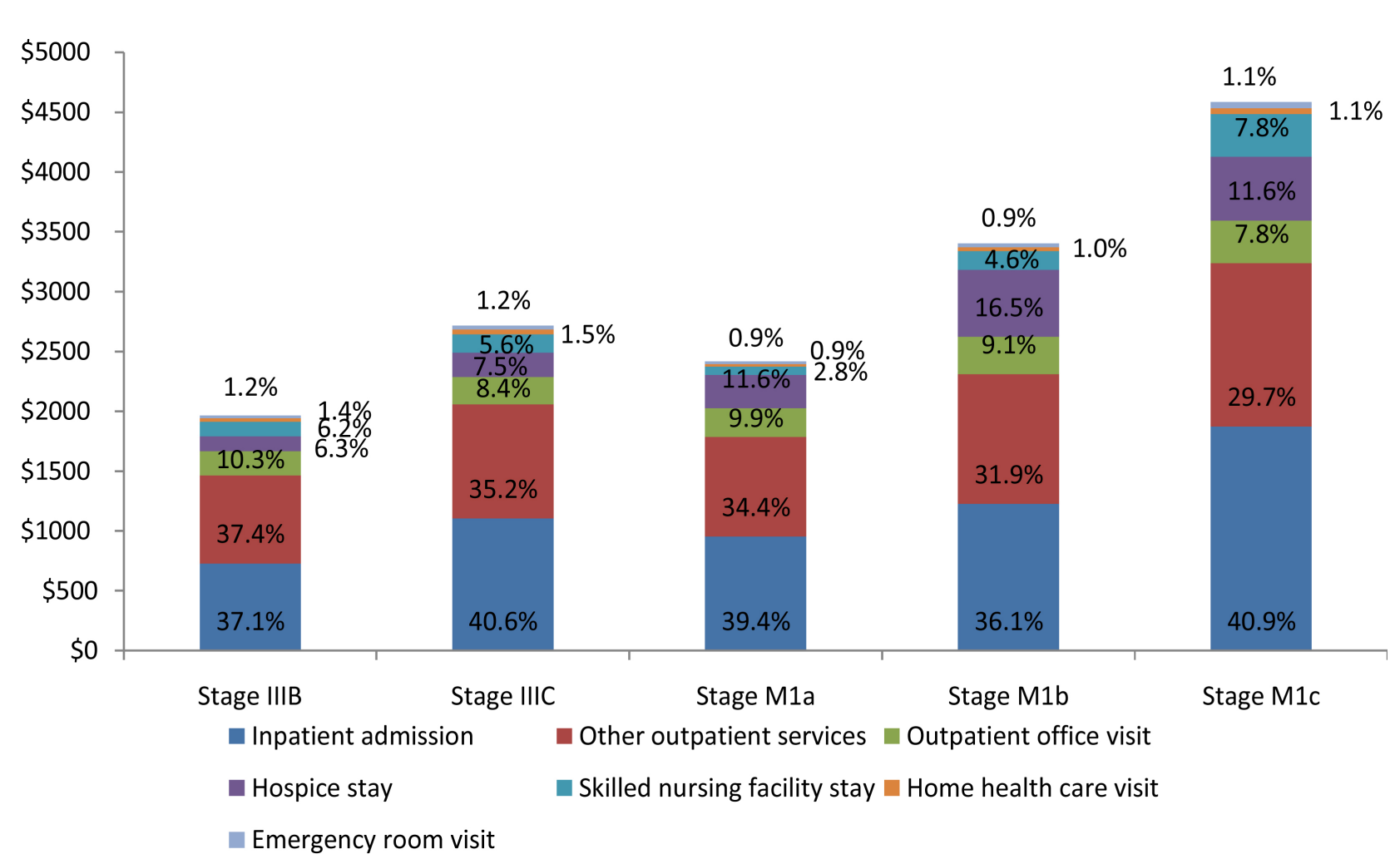

Figure 1. Per-patient per-month (PPPM) all-cause direct medical costs for patients diagnosed with advanced melanoma, by stage of disease at diagnosis.

2009 found that all-cause medical costs of these patients are high and increase with disease stage advances. Mean total PPPM costs were estimated to range from $\$ 1966$ among patients diagnosed at stage IIIB to $\$ 4585$ among patients diagnosed at stage M1c. Costs for outpatient services accounted for 38.7\% - 48.9\% of total costs, while inpatient admissions accounted for $36.1 \%-40.9 \%$ of total costs. As there appeared to be similar utilization across stage for most service types when evaluating the proportion of patients with at least one claim, it is possible that the substantial increase in costs across stages reflects more frequent contact with the healthcare system or more involved in intensive care.

Other published analyses have examined healthcare costs of patients with melanoma in the US. A systematic review by Guy and colleagues in 2012 examined 19 publications from 1990 to 2011 [6]. Despite variations in the populations studied and the costing approach used, they found that medical costs were higher among patients diagnosed with late-stage melanoma compared to those diagnosed at early-stage disease [6].

Two of the US analyses identified by Guy, et al. [6] presented costs by phase of care and disease stage [12] [13]. Using SEER-Medicare data from 1991 to 1996 and 1997 AJCC staging, Seidler, et al., found the average monthly per-patient melanoma costs were $\$ 1402$ during the initial phase (the first four months following diagnosis), \$576 during the interim phase (time after diagnosis when average monthly charges dropped by more than half), and $\$ 2513$ during the ter- 
minal phase (the six months prior to death) of disease progression for patients across all disease stages [12]. Costs were highest for patients diagnosed at stage III and stage IV disease during the initial phase (\$2594 and \$2541, respectively) [12]. Costs stratified by venue of service (i.e., inpatient, outpatient, SNF, HHC) were not reported [12].

Yabroff and colleagues conducted a similar analysis using SEER-Medicare data from 1999 to 2003 and defined phase differently: initial (first 12 months after diagnosis), continuing (months between initial and last phases), and last (last 12 months of life) [13]. The researchers compared cancer patients to non-cancer patients to determine net costs of melanoma in 2004 US \$ [13]. Like Seidler, et al., [12] Yabroff, et al. reported that the net cost of care was highest in the last year of life, and net costs in all phases were higher for patients with distant metastases than those with localized disease (initial $=\$ 21,717$ vs. $\$ 3211$; last $=$ $\$ 46,177$ vs. $\$ 20,145)$ [13].

The systematic review by Guy, et al. [6], also identified four U.S. analyses that presented costs by stage of disease only [14] [15] [16] [17]. The earliest of the four studies was published by Tsao, et al., in 1998 [14]. It should be noted that costs reported by Tsao et al. do not represent actual paid amounts for a population of melanoma patients, but rather a model with a number of assumptions, some of which have been questioned [14]. A similar model-based analysis was conducted by Alexandrescuto to estimate costs by stage over a five-year period, with stage defined by the stage of the primary tumour along with thickness and presence of ulceration [15]. Total five-year costs for stage T3a melanoma were $\$ 35,407$ (in 2008 US $\$$ ) compared to $\$ 38,335$ for stage T3b melanoma, $\$ 105,479$ for stage T4a melanoma, and $\$ 110,150$ for stage T4b melanoma [15]. Hillner and colleagues examined the procedures for 100 patients with metastatic melanoma from 1997-1998 and projected that total average cost per patient was $\$ 59,400$, more than $60 \%$ of which was for inpatient care [16].

The study most directly comparable to the analysis presented here was conducted by Davis and colleagues using SEER-Medicare data from 1991-2005 [17]. Davis, et al., also found that healthcare costs of patients with melanoma increase with advanced stage and that hospital services were the main cost driver [17]. They reported that the costs for patients with stage IV melanoma were substantially higher $(\$ 11,471)$ than costs for patients with stage IIIA/B (\$3395) or IIIC (\$6885) [17]. Although they used older data, their cost estimate for stage IV is much higher than the estimates reported in our study [17]. One potential explanation is that Davis, et al., removed patients with HMO insurance [17] while about one-third of our study population was enrolled in an HMO. When HMO patients are removed from our analysis, the costs do increase (stage IIIB = $\$ 2492$; stage IIIC $=\$ 3296$; stage $\mathrm{Mla}=\$ 3000$; stage $\mathrm{M} 1 \mathrm{~b}=\$ 4420$; stage M1c $=$ \$5592). In addition to the aforementioned reason, the costs differ between the two studies because the cost estimates reported by Davis, et al., were adjusted for patients' characteristics with a multivariable analysis [17] while our costs are 
unadjusted. In a poster presented prior to the publication of their manuscript, Davis and colleagues reported unadjusted costs for the same sample of patients [18]. These costs were lower than those from their later multivariable analysis (stage III A/B $=\$ 2536$, stage III C $=\$ 4880$, and stage IV $=\$ 8190$ ) [18]. While still higher than ours, the difference between the cost estimates is smaller.

The interpretation and generalizability of our findings are subject to several limitations. First, the reported costs are likely an underestimate of total healthcare costs. Medicare Part A and B do not cover outpatient prescription medications, though oral chemotherapeutic agents may appear in the Durable Medical Equipment (DME) file if the orally administered medication is a substitute for an intravenous medication. Following the introduction of Medicare Part D in 2006, outpatient pharmacy claims were captured for patients with Part D enrolment. The DME file and Part D files were not included in this analysis. Additionally, patients who were enrolled in an HMO (about $31 \%$ of the study sample) may have incomplete claims and thus incomplete cost information. When excluding patients with HMO enrolment, average PPPM costs increased by $\$ 600$ to $\$ 1200$ across all cohorts. Second, this study reported all-cause costs and did not adjust for comorbidities and other confounding factors. Due to the lack of information on reimbursement amount from payers other than Medicare and patients' out-of-pocket payment, costs reported in this analysis included Medicare payment only. Future studies that report total reimbursed amount from all payers, melanoma-specific costs, and adjust for confounding factors across disease stages will help better understand the disease specific burden. Third, the SEER data is drawn from 18 regions throughout the United States, and migration in and out of these areas does affect follow-up [19]. Because migration should not disproportionately affect one region, and Medicare is a federal program, migration should not affect costs in any differential way. Fourth, information on disease progression is not available in SEER, thus, this study only examined cost by stage at diagnosis. Fifth, treatment landscape for metastatic melanoma has been changing as some new treatment options have been approved by the US Food and Drug Administration (FDA) since 2011. The current study does not capture the costs of these new treatments. Finally, healthcare utilization and costs were analysed using SEER-Medicare data, and older patients may have very different costs compared to a younger population. Therefore, results from this study may not be generalizable to the whole population of melanoma patients in the US.

Despite these limitations, we believe this study contributes to the literature quantifying the cost of melanoma care among the high-risk elderly population using updated staging information and more recent claims data. Additional research is needed to ascertain the relative proportion of overall medical costs directly attributable to melanoma treatment and the degree to which primary prevention and early detection of melanoma, including care coordination and other care management programs, may reduce the overall cost burden of melanoma in the US. Future research that captures the current treatment landscape and their 
impact on healthcare costs will also be needed to provide the most updated picture of metastatic melanoma.

\section{Conclusion}

Healthcare costs for treating patients with metastatic melanoma increase by disease stage. The cost of care was more than double among patients with late stage compared to those with early stage. Treatments demonstrating ability to prevent disease progression from early stage to late stage may confer an economic benefit among other clinical advantages.

\section{Acknowledgements}

This paper benefited from the substantial editorial contributions of Allison Krug, Truven Health Analytics, an IBM Company.

\section{Conflicts of Interest}

Zhongyun Zhao and Beth Barber are employees of Amgen and hold Amgen stocks. Xue Song, Amanda Farr, Boris Ivanov and Marilyn Novich do not have any relationships to declare.

\section{Funding}

The current study was sponsored by Amgen, Inc.

\section{References}

[1] American Cancer Society (2013) Cancer Facts \& Figures 2013. American Cancer Society, Atlanta.

http://www.cancer.org/acs/groups/content/@epidemiologysurveilance/documents/d ocument/acspc-036845.pdf

[2] Nguyen, D.X., Bos, P.D. and Massague, J. (2009) Metastasis: From Dissemination to Organ-Specific Colonization. Nature Reviews Cancer, 9, 274-284. https://doi.org/10.1038/nrc2622

[3] GLOBOCAN (2012) Estimated Cancer Incidence, Mortality and Prevalence Worldwide. http://globocan.iarc.fr/Default.aspx

[4] Balch, C.M., Gershenwald, J.E., Soong, S.J., Thompson, J.F., Atkins, M.B., Byrd, D.R., et al. (2009) Final Version of 2009 AJCC Melanoma Staging and Classification. Journal of Clinical Oncology, 27, 6199-6206. https://doi.org/10.1200/JCO.2009.23.4799

[5] Song, X., Zhao, Z., Barber, B., Farr, A.M., Ivanov, B. and Novich, M. (2015) Overall Survival in Patients with Metastatic Melanoma. Current Medical Research and Opinion, 31, 987-991. https://doi.org/10.1185/03007995.2015.1021904

[6] Guy Jr., G.P., Ekwueme, D.U., Tangka, F.K. and Richardson, L.C. (2012) Melanoma Treatment Costs: A Systematic Review of the Literature, 1990-2011. American Journal of Preventive Medicine, 43, 537-545. https://doi.org/10.1016/j.amepre.2012.07.031

[7] Greene, F.L., Page, D.L., Fleming, I.D., Fritz, A., Balch, C.M., Haller, D.G., Morrow M., Eds. (2002) American Joint Committee on Cancer: AJCC Cancer Staging Man- 
ual. 6th Edition, Springer, New York.

[8] National Cancer Institute (2012) US Department of Health and Human Services; National Institutes of Health. SEER... as a Research Resource.

https://seer.cancer.gov/about/factsheets/SEER_brochure.pdf

[9] National Cancer Institute. US Department of Health and Human Services; National Institutes of Health. Data Flow in NCI's SEER Registries. https://seer.cancer.gov/registries/

[10] National Cancer Institute (2013) US Department of Health and Human Services; National Institutes of Health. SEER Program Coding and Staging Manual. https://seer.cancer.gov/archive/manuals/2013/SPCSM_2013_maindoc.pdf

[11] National Cancer Institute (2014) SEER-Medicare: How the SEER \& Medicare Data Are Linked. http://appliedresearch.cancer.gov/seermedicare/overview/linked.html

[12] Seidler, A.M., Pennie, M.L., Veledar, E., Culler, S.D. and Chen, S.C. (2010) Economic Burden of Melanoma in the Elderly Population: Population-Based Analysis of the Surveillance, Epidemiology, and End Results (SEER)-Medicare Data. Archives of Dermatology, 146, 249-256.

https://doi.org/10.1001/archdermatol.2009.389

[13] Yabroff, K.R., Lamont, E.B., Mariotto, A., Warren, J.L., Topor, M., Meekins, A., et al. (2008) Cost of Care for Elderly Cancer Patients in the United States. Journal of the National Cancer Institute, 100, 630-641. https://doi.org/10.1093/jnci/djn103

[14] Tsao, H., Rogers, G.S. and Sober, A.J. (1998) An Estimate of the Annual Direct Cost of Treating Cutaneous Melanoma. Journal of the American Academy of Dermatology, 38, 669-680. https://doi.org/10.1016/S0190-9622(98)70195-1

[15] Alexandrescu, D.T. (2009) Melanoma Costs: A Dynamic Model Comparing Estimated Overall Costs of Various Clinical Stages. Dermatology Online Journal, 15, 1.

[16] Hillner, B.E., Kirkwood, J.M. and Agarwala, S.S. (2001) Burden of Illness Associated with Metastatic Melanoma: An Audit of 100 Consecutive Referral Center Cases. Cancer, 91, 1814-1821. https://doi.org/10.1002/1097-0142(20010501)91:9<1814::AID-CNCR1201>3.0.CO;2 $-\mathrm{W}$

[17] Davis, K.L., Mitra, D., Kotapati, S., Ibrahim, R. and Wolchok, J.D. (2009) Direct Economic Burden of High-Risk and Metastatic Melanoma in the Elderly: Evidence from the SEER-Medicare Linked Database. Applied Health Economics and Health Policy, 7, 31-41. https://doi.org/10.1007/BF03256140

[18] Davis, K.L., Mitra, D. and Kotapati, S. (2008) Direct Economic Burden of High-Risk and Metastatic Melanoma: Evidence from the SEER-Medicare Linked Database. ISPOR 13 th Annual International Meeting, Toronto, 3-7 May 2008.

[19] Yu, J.B., Gross, C.P., Wilson, L.D. and Smith, B.D. (2009) NCI SEER Public-Use data: Applications and Limitations in Oncology Research. Oncology (Williston Park), 23, 288-289. 